\title{
Determinantes dos Altos Deságios nos Leilões de Transmissão de Energia Elétrica no Brasil entre 1999-2010*
}

\author{
Katia Rocha ${ }^{\dagger}$, Ajax Moreira ${ }^{\ddagger}$, Rodrigo Limp ${ }^{\S}$
}

\author{
Conteúdo: 1. Introdução; 2. O Leilão de Transmissão e as Características dos Proponentes \\ Vencedores; 3. Modelo Econométrico; 4. Conclusões. \\ Palavras-chave: Leilões de Transmissão Elétrica no Brasil, Economia da Regulação, Teoria de \\ Leilões, Investimentos em Infraestrutura, Investimento Público e Privado. \\ Códigos JEL: D44, L51, L53.
}

O artigo analisa os determinantes dos altos deságios nos leilões de transmissão de energia elétrica no Brasil entre 1999-2010 através de um modelo econométrico baseado em Heckman (1979) considerando a heterogeneidade entre os lances vencedores e perdedores, e a endogeneidade desta clivagem. A partir do conjunto total de lances, explicita-se a heterogeneidade entre os grupos e corrige-se o respectivo viés devido à endogeneidade desta classificação. 0 objeto de pesquisa se justifica uma vez que estudos que focam apenas nos lances vencedores e que ignoram a correção devido à endogeneidade da seleção do grupo vencedor podem conduzir a conclusões impróprias.

This paper investigates the determinants of the difference between reserve prices and winning bids in the transmission electricity auctions in Brazil from 1999 to 2010, by using an econometric approach based on Heckman (1979) that considers the heterogeneity among winner's and loser's bids, and the endogeneity of that selection. Given the full sample of winner's and loser's bids, the heterogeneity of the groups is modeled and the bias from the classification endogeneity is corrected. The approach of this research is justified by the fact that studies that focus only on winning

\footnotetext{
*Os autores agradecem à Superintendência de Concessões e Autorizações de Transmissão e Distribuição - SCT da Agência Nacional de Energia Elétrica (ANEEL) pela disponibilização de dados, em especial a Jandir Amorim Nascimento e a Erison Honda Xavier pelas críticas e contribuições recebidas ao longo desse estudo.

${ }^{\dagger}$ Economista da Diretoria de Estudos Macroeconômicos do IPEA. AV. Presidente Antônio Carlos 51 / 17. Castelo. 20020-010. Rio de Janeiro. Brasil tel: +(55)(21)(35158658); fax: +(55)(21)(35158615). E-mail: katia.rocha@ipea.gov . br

$\ddagger$ Coordenador de Economia Financeira Diretoria de Estudos Macroeconômicos do IPEA. E-mail: ajax.moreira@ipea.gov.br

${ }^{\S}$ Especialista em Regulação da Superintendência de Concessões e Autorizações de Transmissão e Distribuição da ANEEL. E-mail: rodrigolimp@aneel.gov.br
} 
bids and ignore the endogeneity of the winning group selection can lead to misleading conclusions.

\section{INTRODUÇÃO}

O novo marco regulatório do setor elétrico brasileiro, implementado pela Lei 10.848, de 15/03/2004, e regulamentado pelo Decreto 5.163, de 30/07/2004, possui como principais objetivos: "garantir a segurança do suprimento de energia elétrica; promover a modicidade tarifária por meio da contratação eficiente e; remunerar de forma justa os investimentos em capital".

A segurança do suprimento é garantida por uma série de medidas, entre as quais se destacam: a realização de leilões para outorga da expansão da geração e transmissão nos quais os licitantes vencedores celebram contratos bilaterais de longo prazo com as distribuidoras; a exigência de $100 \%$ de contratação da demanda pelas distribuidoras; contrato lastreado em capacidade firme de geração; e monitoramento permanente do setor.

Em um sistema predominantemente hidrelétrico como o brasileiro, as linhas de transmissão exercem um papel fundamental de interligação e remanejamento de recursos hídricos. Dessa forma, pode-se dizer que o investimento em novas linhas de transmissão equivalem a "usinas virtuais", já que o transporte de energia de um lugar para outro pode substituir a necessidade de construção de novas usinas. $^{1}$

A estimativa da evolução física dos sistemas de transmissão no período 2011-2020 segundo o Plano Decenal de Expansão de 2020 (PDE 2020) relativamente às linhas de transmissão (km) e à capacidade de transformação (MVA) são apresentadas nas Tabelas 1 e 2.

Tabela 1: Estimativa da Evolução Física de Linhas de Transmissão (km)

\begin{tabular}{lccccccc}
\hline \multicolumn{1}{c}{ Tensão } & $750 \mathrm{kV}$ & $\pm 600 \mathrm{kV}$ & $500 \mathrm{kV}$ & $440 \mathrm{kV}$ & $345 \mathrm{kV}$ & $230 \mathrm{kV}$ & Total \\
\hline Existente em 2010 & 2.698 & 1.612 & 34.190 & 6.809 & 9.991 & 44.349 & 99.649 \\
$2011-2015$ & - & 7.050 & 15.474 & 9 & 252 & 9.512 & 32.297 \\
$2016-2020$ & - & 3.750 & 6.176 & - & - & 330 & 10.256 \\
Total 2011-2020 & - & 10.800 & 21.650 & 9 & 252 & 9.842 & 42.553 \\
Estimativa 2020 & 2.698 & 12.412 & 55.840 & 6.818 & 10.243 & 54.191 & 142.202 \\
\hline
\end{tabular}

Fonte: Plano Decenal de Expansão de 2020 - EPE.

Segundo o Plano Decenal de Expansão de 2020, o valor total dos investimentos previstos para expansão da transmissão de energia elétrica atinge cerca de R\$46,4 bilhões, sendo R\$ 30 bilhões (64.7\%) em linhas de transmissão e R\$ 16,4 bilhões (35.3\%) em subestações. Considerando apenas as novas instalações de transmissão previstas e ainda não licitadas, o valor total resulta na ordem de R\$ 29 bilhões, sendo cerca de R\$ 19 bilhões (65.5\%) em linhas de transmissão e R\$ 10 bilhões (34.5\%) em subestações.

\footnotetext{
${ }^{1}$ As linhas de transmissão de energia elétrica são indispensáveis para interligar os submercados de energia elétrica e conectar pontos distantes dos centros de geração, permitindo a promoção de um processo de equalização dos preços da energia por meio da minimização dos estrangulamentos entre os submercados, resultando na adoção de um despacho ótimo do parque gerador, sendo uma forma barata e rápida de atender à demanda nestes locais, se comparada à instalação de usinas de geração. A interligação elétrica entre regiões possibilita ainda a otimização energética das bacias hidrográficas, com o aproveitamento de suas diversidades hidrológicas, além de aumentar a segurança do sistema.
} 
Tabela 2: Estimativa da Evolução Física de Transformação (MVA)

\begin{tabular}{lcccccc}
\hline \multicolumn{1}{c}{ Tensão } & $750 \mathrm{kV}$ & $500 \mathrm{kV}$ & $440 \mathrm{kV}$ & $345 \mathrm{kV}$ & $230 \mathrm{kV}$ & Total \\
\hline Existente em 2010 & & & & & & 222.119 \\
$2011-2015$ & 1500 & 24.830 & 3.733 & 9.072 & 18.295 & 57.430 \\
2016-2020 & 0 & 9.497 & 0 & 100 & 2.224 & 11.821 \\
Total 2011-2020 & 1.500 & 34.327 & 3.733 & 9.172 & 20.519 & 69.251 \\
Estimativa 2020 & & & & & & 291.370
\end{tabular}

Fonte: Plano Decenal de Expansão de 2020 - EPE.

De janeiro de 1999 a dezembro 2010, a Agência Nacional de Energia Elétrica (ANEEL) licitou 135 lotes de linhas de transmissão (km) e/ou subestação (MVA), que totalizam 37.454,6 km e 63.772 MVA, como ilustrado na Tabela 3, perfazendo um total de 576 lances.

Tabela 3: Lotes de Linhas de Transmissão e Subestação Leiloados

\begin{tabular}{ccc}
\hline Ano & km & MVA \\
\hline 1999 & 758 & 772 \\
2000 & 4495 & 3900 \\
2001 & 711 & 1200 \\
2002 & 1850,4 & 0 \\
2003 & 1787 & 0 \\
2004 & 3887,4 & 2350 \\
2005 & 3055,8 & 4000 \\
2006 & 3275 & 7304 \\
2007 & 1930 & 660 \\
2008 & 10507,8 & 25425 \\
2009 & 3382,2 & 13900 \\
2010 & 1815 & 4261 \\
\hline Fonte: Elaboração Própria e \\
dados ANEEL.
\end{tabular}

Nestes leilões, houve significativo deságio médio anual conforme ilustra a Figura 1.

Poucos são os artigos acadêmicos encontrados na literatura que analisam os determinantes dos altos deságios médios praticados no mercado de transmissão elétrica brasileiro. Castro e Brandão (2007a,b) argumentam que os altos deságios estão relacionados, especialmente, à queda do Risco Brasil, à alta liquidez internacional, à dinâmica das empresas investidoras epecistas (do inglês Engineering Procurement Contract - EPC), cujo objeto da contratação é a entrega do empreendimento pronto, acabado e em operação, e finalmente, aos grandes grupos espanhóis devido a um conjunto de vantagens viabilizado pela estrutura empresarial dessas companhias, passando por facilidades no acesso ao crédito, engenharia financeira e ganhos tributários. Carlos e Saraiva (2010) argumentam, a partir de 
Figura 1: Deságio médio anual (\%)

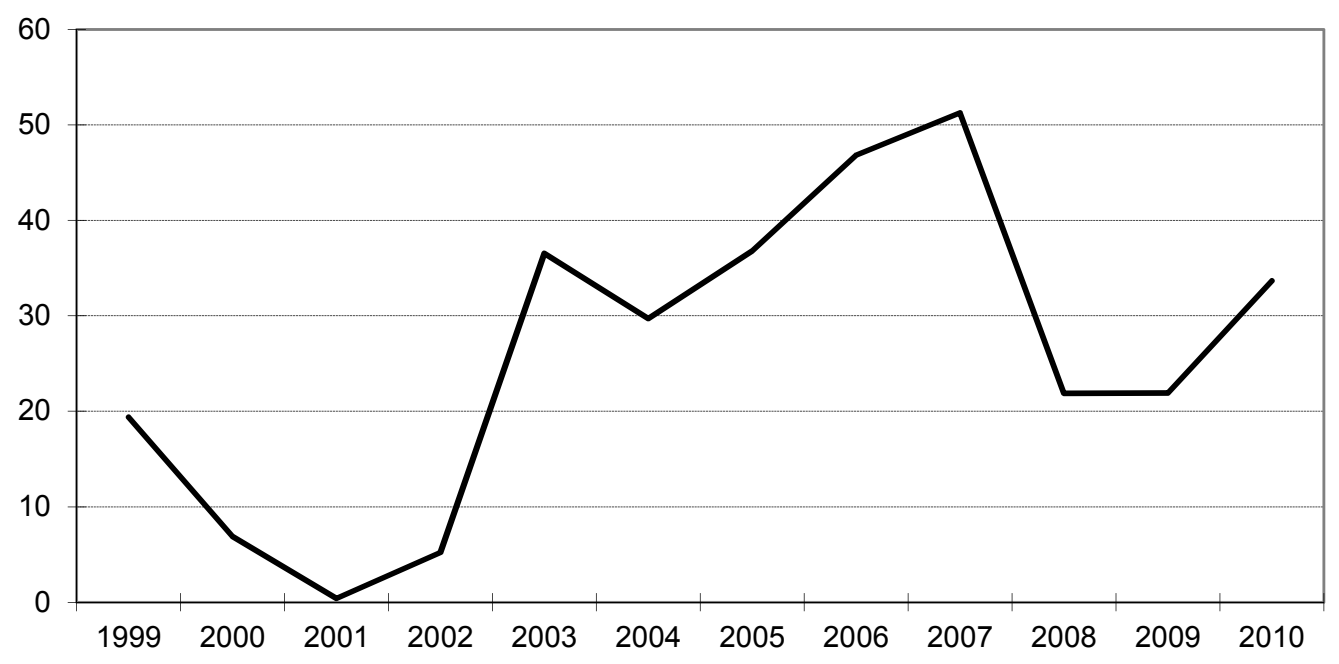

Fonte: Elaboração Própria e dados ANEEL.

um modelo econométrico focando nas linhas de transmissão e nos lances vencedores, que diversos fatores tais como o número de competidores, benefícios fiscais ou tributários, extensão da linha, custo do investimento, e principalmente, ganhos de escala e sinergias de empresas que já operavam da região, são os principais determinantes dos altos deságios praticados no período. Motta e Ramos (2011) e Hirota (2006) através da aplicação de versões do modelo de Gandal (1997) confirmam a importância da interdependência e economias de escala como fator determinante para os altos deságios.

O objetivo desse estudo é analisar os determinantes dos deságios no setor de transmissão elétrica brasileiro no período de 1999-2010 através de um modelo econométrico que considera a heterogeneidade entre os lances vencedores e perdedores, e a endogeneidade desta clivagem. Para isto utiliza o estimador proposto por Heckman (1979) apresentado em Cameron e Trivedi (2005). Dessa forma, analisa-se o conjunto total de lances (vencedores e perdedores) e explicita-se a heterogeneidade entre o grupo vencedor e perdedor; além de corrigir para o viés devido à endogeneidade desta classificação (vencedor/perdedor). Esse é um aspecto importante, mas negligenciado em estudos anteriores, que focam apenas nos lances vencedores e ignoram a heterogeneidade entre os grupos. Neste estudo, a condição de vencedor revela a heterogeneidade entre os agentes, seja devido à assimetria de informação, ou sinergias locacionais (interdependência e ganhos de escala devido à empresa já possuir investimentos na região do lote a ser leiloado). Dessa forma, o estudo se justifica como objeto de pesquisa uma vez que estudos voltados somente para lances vencedores, ou que ignoram a correção devido à endogeneidade da seleção do grupo vencedor podem levar a conclusões errôneas. A Seção 2 apresenta uma breve descrição da sistemática dos leilões e apresenta as estatísticas relativas aos lances obtidos e aos tipos de proponentes com o intuito de proporcionar certa intuição sobre a característica dos proponentes vencedores; a Seção 3 apresenta o modelo econométrico proposto que analisa os determinantes dos deságios; e finalmente a última seção conclui e propõe extensões naturais ao estudo. 


\section{2. $O$ LEILÃO DE TRANSMISSÃO E AS CARACTERÍSTICAS DOS PROPONENTES VENCEDORES}

Segundo os editais do leilão divulgados pela ANEEL, constitui objeto do leilão a contratação de serviço público de transmissão (linha de transmissão e/ou subestação), mediante outorga, pela menor Receita Anual Permitida (RAP) proposta, de forma individualizada para cada lote, incluindo a construção, a montagem, a operação e a manutenção das instalações de transmissão, por um período de 30 (trinta) anos, contados a partir da data de assinatura do respectivo contrato de concessão. A RAP vencedora, estabelecida em reais por ano ( $\mathrm{R} \$ \mathrm{ano}$ ) e distribuída em duodécimos, correspondente a uma receita em reais por mês (R\$/mês), será objeto de reajustes anuais pelo Índice Nacional de Preços ao Consumidor Amplo - IPCA e de revisões tarifárias a cada cinco anos, nos termos do contrato de concessão e em conformidade com os parâmetros regulatórios estabelecidos pela ANEEL.

A Receita Anual Permitida Máxima (preço teto do leilão) é determinada pela ANEEL através do método do fluxo de caixa descontado, considerando como fluxos de caixa a série de recebimentos anuais que amortiza os investimentos em questão a um custo de oportunidade de capital (rentabilidade) definido previamente pelo regulador. ${ }^{2}$ Para tanto, a ANEEL se utiliza do conhecimento disponível a respeito dos parâmetros médios de mercado, como custo operacional, de manutenção e investimentos iniciais através de um banco de preços de referência atualizado.

O formato dos leilões das linhas de transmissão equivale a um leilão híbrido entre dois modelos um leilão de primeiro preço selado (Dutch Auction) seguido de um leilão de viva-voz (English Auction). ${ }^{3}$ Na primeira fase, cada competidor realiza um lance através de envelope lacrado, contendo a proposta financeira, ou seja, o valor da RAP em reais por ano. Será declarada vencedora de cada lote a proponente que ofertar, em envelope lacrado, o menor valor da RAP para exploração da concessão, desde que os valores ofertados pelas demais proponentes sejam superiores a 5\% (cinco por cento) do valor ofertado pela menor proposta financeira apresentada em envelope lacrado. Caso haja empate, ou pelo menos um lance suficientemente próximo ao menor lance, o leilão prosseguirá, com lances sucessivos efetuados a viva-voz, cujo valor inicial será o da menor oferta apurada nos envelopes para cada lote. ${ }^{4}$

Segundo o edital de licitação para contratação de serviço público de transmissão, poderão participar como proponentes pessoas jurídicas de direito privado nacionais (estatais ou particulares) ou estrangeiras, bem como fundos de investimento em participações (FIP's), isoladamente ou reunidas em consórcio (com indicação da empresa líder).

A partir das informações disponíveis, elaboramos duas tipologias para os proponentes:

a) proponente líder: estatais nacionais; empresas nacionais privadas; grupos estrangeiros;

b) forma de participação: consórcio; estatal nacional isoladamente, empresa nacional privada isoladamente ou empresa estrangeira isoladamente.

O grau de concorrência de um leilão aumenta com o número de proponentes que realizam lances. Dessa forma os resultados foram tabulados distinguindo-os segundo o número de concorrentes.

A existência de um lance destoante no leilão - muito menor do que os demais lances - é um indício do interesse especial do vencedor proponente naquele lote (e possivelmente relacionado com o efeito

\footnotetext{
${ }^{2}$ Maiores informações sobre métodos de valoração de ativos regulatórios podem ser encontradas em CC-MED (2002).

${ }^{3}$ Segundo Klemperer (2002), os leilões híbridos combinam as características positivas dos dois tipos isolados de leilões. O leilão viva-voz associa maior valor a quem mais valora o bem, pois cada competidor pode exceder um lance a qualquer momento, muito embora, esse tipo de leilão está sujeito a comportamentos de conluio. O leilão de preço selado não apresenta características de retaliação ou conluio encorajando a entrada de mais participantes, porém pode ser ineficiente do ponto de vista alocativo, pois falha em alocar o bem a quem mais o valoriza.

${ }^{4}$ Dutra e Menezes (2002) argumentam que o leilão híbrido adotado proporciona uma maior renda esperada ao leiloeiro se comparado a outras configurações de leilões.
} 
conhecido como "maldição do vencedor"). Definimos um lance como sendo destoante quando o deságio é maior do que um valor crítico calculado com os demais lances do mesmo lote. ${ }^{5}$ Este valor crítico, calculado para os leilões com mais do que no mínimo de três proponentes, caracteriza o extremo da distribuição dos demais lances, indicando, portanto, que o lance vencedor destoa de forma estatística dos demais lances.

A Tabela 4 apresenta o número de lances segundo as duas tipologias propostas e por número de proponentes $(n)$. A quarta linha resume os leilões com poucos proponentes $(n \leq 3)$, quinta linha a dos demais leilões $(n>3)$, e as duas penúltimas linhas indicam os lances normais e os lances que foram considerados destoantes.

Tabela 4: Número de lances por proponentes e formas de participação no leilão

\begin{tabular}{l|c|c|c|c|c|c|c|c}
\hline \multirow{2}{*}{ \#proponentes por lote } & \multicolumn{3}{|c|}{ Proponente líder } & \multicolumn{3}{c|}{ Forma de participação } & \multirow{2}{*}{ Total } \\
\cline { 2 - 7 } & Nacional & Estrangeiro & Estatal & Consórcio & $\begin{array}{c}\text { Nacional } \\
\text { isolado }\end{array}$ & $\begin{array}{c}\text { Estrangeiro } \\
\text { isolado }\end{array}$ & $\begin{array}{c}\text { Estatal } \\
\text { isolado }\end{array}$ & \\
\hline$n=1$ & 4 & 1 & 15 & 6 & 3 & 1 & 10 & 20 \\
$n=2$ & 20 & 8 & 24 & 28 & 13 & 4 & 7 & 52 \\
$n=3$ & 32 & 17 & 20 & 34 & 15 & 12 & 8 & 69 \\
$n \leq 3$ & 56 & 26 & 59 & 68 & 31 & 17 & 25 & 141 \\
$n>3$ & 146 & 199 & 90 & 111 & 119 & 179 & 26 & 435 \\
Lance Normal $\mid n>3$ & 143 & 192 & 77 & 103 & 116 & 173 & 20 & 412 \\
Lance Destoante $\mid n>3$ & 3 & 7 & 13 & 8 & 3 & 6 & 6 & 23 \\
Total & 202 & 225 & 149 & 179 & 150 & 196 & 51 & 576 \\
\hline
\end{tabular}

Fonte: Elaboração Própria e dados ANEEL.

Os resultados da Tabela 4 mostram que:

a) Lotes com poucos proponentes $(n \leq 3)$ são dominados por empresa estatal líder (59/141) e por empresa nacional líder (56/141);

b) Todos os tipos de empresa realizam lances destoantes, sendo maiores nas estatais líderes (13/23).

A Tabela 5 apresenta a distribuição dos lances vencedores segundo as mesmas características. Os resultados da Tabela 5 mostram que:

a) Praticamente metade (68/135) dos lotes leiloados tiveram menos do que três proponentes, sugerindo um interesse diferenciado entre os lotes;

b) A maioria dos lotes com menor número de proponentes $(n \leq 3)$ foi vencido por empresa estatal líder (44/68) ou por estatal isoladamente (23/68);

c) $34 \%(23 / 67)$ dos lances vencedores com mais de três proponentes $(n>3)$ foram classificados como destoantes;

d) A estatal líder é responsável por 57\% do total de lances destoantes (13/23), valor muito superior a dos proponentes estrangeiros ou nacionais quando líder.

A Tabela 6 apresenta a razão entre as medidas das duas tabelas anteriores, e equivale a probabilidade condicional de vencer o leilão dado o tipo de proponente e formas de participação.

\footnotetext{
${ }^{5} \mathrm{O}$ valor crítico do lance destoante foi definido como a diferença entre o menor e o maior deságio somada ao deságio mediano. Esta medida é uma adaptação para pequenas amostras do critério de identificação de pontos espúrios apresentada em Tukey (1977).
} 
Tabela 5: Lances vencedores por proponentes e formas de participação no leilão

\begin{tabular}{|c|c|c|c|c|c|c|c|c|}
\hline \multirow[b]{2}{*}{ \#proponentes por lote } & \multicolumn{3}{|c|}{ Proponente líder } & \multicolumn{4}{|c|}{ Forma de participação } & \multirow[b]{2}{*}{ Total } \\
\hline & Nacional & Estrangeiro & Estatal & Consórcio & $\begin{array}{c}\text { Nacional } \\
\text { isolado }\end{array}$ & $\begin{array}{c}\text { Estrangeiro } \\
\text { isolado }\end{array}$ & $\begin{array}{l}\text { Estatal } \\
\text { isolado }\end{array}$ & \\
\hline$n=1$ & 4 & 1 & 15 & 6 & 3 & 1 & 10 & 20 \\
\hline$n=2$ & 4 & 3 & 18 & 15 & 2 & 2 & 6 & 25 \\
\hline$n=3$ & 7 & 5 & 11 & 10 & 3 & 3 & 7 & 23 \\
\hline$n \leq 3$ & 15 & 9 & 44 & 31 & 8 & 6 & 23 & 68 \\
\hline$n>3$ & 9 & 27 & 31 & 21 & 9 & 24 & 13 & 67 \\
\hline Lance Normal $\mid n>3$ & 6 & 20 & 18 & 13 & 6 & 18 & 7 & 44 \\
\hline Lance Destoante $\mid n>3$ & 3 & 7 & 13 & 8 & 3 & 6 & 6 & 23 \\
\hline Total & 24 & 36 & 75 & 53 & 16 & 30 & 36 & 135 \\
\hline
\end{tabular}

Fonte: Elaboração Própria e dados ANEEL.

Tabela 6: Probabilidade de vencer condicional a tipologia e formas de participação

\begin{tabular}{|c|c|c|c|c|c|c|c|c|}
\hline \multirow[b]{2}{*}{ \#proponentes por lote } & \multicolumn{3}{|c|}{ Proponente líder } & \multicolumn{4}{|c|}{ Forma de participação } & \multirow[b]{2}{*}{ Total } \\
\hline & Nacional & Estrangeiro & Estatal & Consórcio & $\begin{array}{c}\text { Nacional } \\
\text { isolado }\end{array}$ & $\begin{array}{c}\text { Estrangeiro } \\
\text { isolado }\end{array}$ & $\begin{array}{l}\text { Estatal } \\
\text { isolado }\end{array}$ & \\
\hline$n=1$ & 1.00 & 1.00 & 1.00 & 1.00 & 1.00 & 1.00 & 1.00 & 1.00 \\
\hline$n=2$ & 0.20 & 0.38 & 0.75 & 0.54 & 0.15 & 0.50 & 0.86 & 0.50 \\
\hline$n=3$ & 0.22 & 0.29 & 0.55 & 0.29 & 0.20 & 0.25 & 0.88 & 0.33 \\
\hline$n \leq 3$ & 0.27 & 0.35 & 0.75 & 0.46 & 0.26 & 0.35 & 0.92 & 0.48 \\
\hline$n>3$ & 0.06 & 0.14 & 0.34 & 0.19 & 0.08 & 0.13 & 0.50 & 0.15 \\
\hline Total & 0.12 & 0.16 & 0.50 & 0.30 & 0.11 & 0.15 & 0.71 & 0.23 \\
\hline
\end{tabular}

Fonte: Elaboração Própria e dados ANEEL.

Os resultados da Tabela 6 mostram que:

a) A probabilidade de vencer o leilão é de $71 \%$ para estatal isolada;

b) A probabilidade de vencer das demais é muito inferior, sendo que a probabilidade de vencer de uma empresa nacional ou estrangeira isolada em lotes com mais do que três proponentes $(n>3)$ é de apenas $8 \%$ e $13 \%$ enquanto novamente a estatal isolada vence em $50 \%$ das vezes.

A Tabela 7 apresenta o efeito destas tipologias sobre os deságios dos leilões.

Os resultados da Tabela 7 mostram que:

a) O aumento do número de proponentes $(n)$ aumenta os deságios, ilustrando o efeito benéfico da concorrência; uma vez que lotes com menos de três proponentes $(n \leq 3)$ resultaram em pequeno de deságio médio (12\%), e os demais lotes, com maior concorrência, apresentaram deságios médios de $24 \%$;

b) Para lotes com menos de três proponentes $(n \leq 3)$, a estatal líder ou isolada apresentou o maior deságio médio de $17 \%$ e $23 \%$ respectivamente;

c) O deságio médio da estatal isolada, $29 \%$, é o maior de todos, seguido dos estrangeiros com $26 \%$ e dos grupos nacionais com $18 \%$; 
Tabela 7: Deságio médio por proponentes e formas de participação no leilão

\begin{tabular}{|c|c|c|c|c|c|c|c|c|}
\hline \multirow[b]{2}{*}{ \#proponentes por lote } & \multicolumn{3}{|c|}{ Proponente líder } & \multicolumn{4}{|c|}{ Forma de participação } & \multirow[b]{2}{*}{ Total } \\
\hline & Nacional & Estrangeiro & Estatal & Consórcio & $\begin{array}{c}\text { Nacional } \\
\text { isolado }\end{array}$ & $\begin{array}{c}\text { Estrangeiro } \\
\text { isolado }\end{array}$ & $\begin{array}{l}\text { Estatal } \\
\text { isolado }\end{array}$ & \\
\hline$n=1$ & 0.10 & 0.00 & 0.08 & 0.08 & 0.13 & 0.00 & 0.09 & 0.08 \\
\hline$n=2$ & 0.10 & 0.09 & 0.18 & 0.13 & 0.11 & 0.09 & 0.31 & 0.13 \\
\hline$n=3$ & 0.09 & 0.08 & 0.22 & 0.13 & 0.12 & 0.10 & 0.33 & 0.13 \\
\hline$n \leq 3$ & 0.10 & 0.08 & 0.17 & 0.13 & 0.12 & 0.09 & 0.23 & 0.12 \\
\hline$n>3$ & 0.18 & 0.26 & 0.30 & 0.24 & 0.19 & 0.27 & 0.29 & 0.24 \\
\hline Lance Normal $\mid n>3$ & 0.18 & 0.26 & 0.28 & 0.23 & 0.19 & 0.27 & 0.24 & 0.23 \\
\hline Lance Destoante $\mid n>3$ & 0.27 & 0.31 & 0.40 & 0.36 & 0.27 & 0.33 & 0.45 & 0.36 \\
\hline Total & 0.16 & 0.24 & 0.26 & 0.18 & 0.18 & 0.26 & 0.29 & 0.22 \\
\hline
\end{tabular}

Fonte: Elaboração Própria e dados ANEEL.

d) A média dos deságios dos lances classificados como destoantes (36\%) é praticamente o dobro da média dos demais deságios (23\%);

e) A estatal líder (40\%) ou de forma isolada (45\%), apresenta o maior deságio médio do lance classificado como destoante, indicando maior propensão à característica conhecida como "maldição do vencedor". 6

A Tabela 8 detalha a formação dos consórcios segundo sua composição e ilustra a importância de cada grupo na participação nos investimentos. As últimas três linhas da tabela apresentam os resultados agregados. As colunas denotadas por (\#) indicam o número de lances, e as colunas denotadas por (\%) indicam a proporção correspondente. A terceira coluna apresenta a probabilidade de vencer no lance realizado por cada tipo de empresa ou consórcio, e a última coluna apresenta a proporção do investimento total que foi realizado pelo tipo de empresa/consórcio.

Os resultados agregados por tipo mostram que:

a) Propostas realizadas por estatais (linha 11) tem 50\% de probabilidade de vencer, fator maior que o dobro das propostas (linhas 12 e 13) onde a empresa estatal está ausente que é de até $20 \%$. Segundo este critério se associar a estatais favorece o sucesso no leilão;

b) A proporção dos investimentos realizados por propostas vencedoras que tenham alguma participação das estatais é de 52\% (linha 11) mas se limita a 8\% (ver linhas 3, 6 e 8) quando excluímos os casos em que as estatais entram em consórcio com grupos nacionais, indicando que as estatais tem operado em parceria com o setor privado nacional;

c) A proporção dos investimentos realizados por propostas vencedoras que tenham alguma participação de empresa nacional é de 63\% (linha 13) mas se limita a 19\% (ver linhas 1, 7 e 10) quando excluímos os casos em que os grupos nacionais entram em consórcio com estatais, confirmando o diagnóstico de intensa parceria entre os grupos nacionais e as empresas estatais.

\section{MODELO ECONOMÉTRICO}

Conforme mencionado anteriormente, a ANEEL estima o valor da Receita Anual Permitida Máxima RAP (preço de reserva) através de um método de valoração de ativos baseados em informações a

\footnotetext{
${ }^{6}$ A maldição do vencedor foi inicialmente apresentado em Capen et alii (1971) e desde então, é um dos conceitos mais aplicados da Teoria de Leilões, sendo mais comum em leilões selados de primeiro preço segundo Thaler (1988).
} 
Tabela 8: Proporção do Investimento realizado por tipo de proponente

\begin{tabular}{l|c|c|c|c|c|c}
\hline & \multicolumn{2}{|c|}{ Lances (a) } & \multicolumn{2}{|c|}{$\begin{array}{c}\text { Lances } \\
\text { vencedores (b) }\end{array}$} & $\begin{array}{c}\text { Prob. vencer } \\
\text { (b)/(a) }\end{array}$ & Investimento \\
\hline & $\#$ & $\%$ & $\#$ & $\%$ & $\%$ & $\%$ \\
Participação em consórcios & 179 & 31 & 53 & 39 & 30 & 55 \\
1-Nacional \& Estrangeiro & 13 & 2 & 3 & 2 & 23 & 3 \\
2-Nacional \& Estatal & 83 & 14 & 30 & 22 & 36 & 26 \\
3-Estatal \& Estrangeiro & 2 & 0 & 1 & 1 & 50 & 0 \\
4-Estatal \& Estrangeiro \& Nacional & 11 & 2 & 6 & 4 & 55 & 18 \\
5-Estrangeiros & 16 & 3 & 3 & 2 & 19 & 2 \\
6-Estatais & 2 & 0 & 2 & 1 & 100 & 0 \\
7-Nacional & 52 & 9 & 8 & 6 & 15 & 6 \\
Participação isolada & 397 & 69 & 82 & 61 & 21 & 45 \\
8-Estatal isolada & 51 & 9 & 36 & 27 & 71 & 8 \\
9-Estrangeira isolada & 196 & 34 & 30 & 22 & 15 & 26 \\
10-Nacional isolada & 150 & 26 & 16 & 12 & 11 & 10 \\
Participação Total (c) & 576 & $100 \%$ & 135 & $100 \%$ & $24 \%$ & $100 \%$ \\
11-Estatal (2+3+4+6+8) & 149 & $26 \%$ & 75 & $56 \%$ & $50 \%$ & $52 \%$ \\
12-Estrangeiro (1+3+4+5+9) & 238 & $41 \%$ & 43 & $32 \%$ & $18 \%$ & $49 \%$ \\
13-Nacional (1+2+4+7+10) & 309 & $54 \%$ & 63 & $47 \%$ & $20 \%$ & $63 \%$ \\
\hline
\end{tabular}

Fonte: Elaboração Própria e dados ANEEL.

respeito dos parâmetros médios de mercado e de um banco de preços de referência atualizado. No entanto, a evolução e análise dos altos deságios médios observados nos 135 lotes leiloados no período de 1999-2010 se justifica como tema de pesquisa, e características como a dinâmica dos fundamentos da economia brasileira, liquidez internacional, além de questões relacionadas à assimetria de informação, ganhos de escala, sinergias e eventuais características dos leilões e proponentes podem e devem ser exploradas. As condições macroeconômicas podem ter se alterado entre o momento em que o projeto foi orçado pela ANEEL até o momento do leilão. Isto pode ser particularmente importante no período em estudo caracterizado por momentos de turbulência econômica doméstica ou externa.

A obrigatoriedade de se constituir uma Sociedade de Propósito Específico (SPE) para participação nos leilões de transmissão para FIP's, pessoas jurídicas de direito privado estrangeiras, consórcios nacionais desde que não tenham sido constituídos com o propósito específico de explorar o serviço público de transmissão, oferece benefícios fiscais (como a possibilidade de adoção da sistemática do Lucro Real ou Lucro Presumido desde que a receita bruta anual não ultrapasse o limite de R\$ 48 milhões) que podem condicionar os deságios. A razão entre a RAP do edital e o investimento orçado é uma medida da taxa interna de retorno, ou rentabilidade do investimento, e naturalmente, projetos com maiores rentabilidades possibilitam maiores deságios. Finalmente, o grau de disputa em certo lote, medido pelo número de proponentes, pode também afetar o deságio.

Além das variáveis acima, o deságio pode ser explicado por componentes não observáveis como assimetria de informação, vantagens decorrentes de características intrínsecas da empresa proponente, ou da proximidade entre os investimentos já realizados pelo proponente na região do lote leiloado (sinergias, interdependência e ganhos de escala). 0 efeito destas variáveis não observáveis (ou de difícil observação) é revelado com a vitória da proposta. Uma forma de tratar essa questão é admitir que estas variáveis não observáveis alteram a relação entre as variáveis explicativas e o deságio, o que implica em admitir a heterogeneidade dos coeficientes do modelo entre os lances perdedores e os vencedores. 
A situação em que temos um modelo para explicar o deságio de cada grupo - vencedor e perdedor e em que a pertinência ao grupo é determinada endogenamente corresponde ao modelo de Roy, apresentado em Cameron e Trivedi (2005), tratável pelo estimador de dois passos proposto por Heckman (1979).

Seja $V$ o conjunto dos lances vencedores e $P$ dos lances perdedores. O vetor $Z$ representa o conjunto das variáveis que explicam a probabilidade de vencer, e que necessariamente não são explicadas pelos deságios, e $X$ o vetor das variáveis explicativas do deságio.

Dessa forma, o modelo proposto pode ser sumarizado pelas Equações (1-3), que representam o estimador de Heckman para os deságios $\left(D_{i}\right)$ dos dois grupos: vencedor e perdedor, bem como a probabilidade do lance ser do tipo vencedor.

$$
\begin{gathered}
\operatorname{prob}(i \in V)=\phi(\delta Z) \\
D_{i}=\alpha_{v} X_{i}+\lambda_{v} \Phi(\delta Z)+e_{i} \quad i \in V \\
D_{i}=\alpha_{p} X_{i}+\lambda_{p} \Phi(\delta Z)+e_{i} \quad i \notin V
\end{gathered}
$$

As variáveis $Z$ explicam a probabilidade de um lance ser vencedor através do modelo probit (1), e as equações (2) e (3) descrevem os deságios dos lances vencedores $(i \in V)$ e perdedores $(i \notin V)$ como função de variáveis explicativas dos deságios $X$ e uma variável inversa de Mills que é calculada a partir dos resultados de (1) e que corrige o viés devido à endogeneidade da seleção da amostra.

A distinção dos lances vencedores dos perdedores é natural, no entanto, esta distinção é endógena, o que implica em viés na estimativa dos parâmetros devido ao efeito de componentes não observadas que tornam um lance vencedor. O estimador proposto por Heckman contorna esta situação, sob a condição de identificação de que pelo menos uma componente de $Z$ não seja componente de $X$, e que esta componente seja um instrumento, no sentido de que não pode ser explicado pelos deságios.

O modelo foi estimado com a rotina Heckman do programa Stata (StataCorp LP) especificada para a estimação em dois passos como sugerido por Cameron e Trivedi (2005), o que garante que a probit associada à equação dos lances vencedores é igual àquela associada a dos lances perdedores. Nesta abordagem, temos variáveis explicativas de dois tipos: as que explicam a probabilidade de vencer $(Z)$, que são características do proponente, e as que explicam o deságio $(X)$ que são características do leilão.

A probabilidade de vencer foi explicada com as tipologias sugeridas, ou seja, a indicação da proponente líder: empresa estatal nacional, estrangeira e nacional, e sua forma de participação no leilão: formação de consórcio ou participação isolada, além de uma variável indicadora construída de sinergia entre o lote leiloado e investimentos anteriores na área. ${ }^{7}$ Todas essas variáveis são exógenas em relação ao deságio.

Cabe ressaltar que os 135 lotes leiloados ocorreram em apenas 22 dias no período de 1999 a 2010, o que restringe muito a variabilidade de informação das variáveis macroeconômicas. Por este motivo resumimos a escolha da variáveis determinantes dos deságios $(X)$ às indicadas abaixo:

\footnotetext{
${ }^{7} \mathrm{~A}$ variável indicadora de sinergia entre uma empresa proponente e o lote leiloado foi construída assumindo a divisão já existente do Sistema Interligado Nacional - SIN (Sudeste/Centro-Oeste, Sul, Nordeste e Norte), e que a estatal atuante em cada região já apresenta sinergia (valor igual a um) com a sua própria região, e que todas as demais empresas passam a ter sinergia com um lote de determinada região sempre que já tiverem vencido um lote anterior na mesma região. Evidentemente, outras variáveis de sinergia, interdependência ou ganhos de escala podem ser elaboradas e sua sofisticação depende do grau de informação disponível. Propomos essa questão como objeto de futuras extensões a esse trabalho.
} 
- Risco Brasil: EMBI+BR, variável que mede o risco país, e que se relaciona com custo de captação no Brasil, aversão ao risco internacional, credibilidade da política fiscal, taxa de câmbio entre outros; ${ }^{8}$

- TIR: taxa de atratividade do investimento, definida como RAP proposta no edital sobre o custo do investimento orçado pela ANEEL;

- Variáveis indicadoras do número $(n)$ de proponentes: $(n=1 ; n=2 ; n=3 ; n=4 ; n>4)$;

- Benefício Fiscal: variável dummy produto da condição do proponente não ser estatal isolada multiplicada pela proposta de valor inferior a R\$ 48milhões, o que corresponde a $72 \%$ dos lances. ${ }^{9}$

A Tabela 9 apresenta os coeficientes estimados de cada modelo, e a coluna HO corresponde à estatística $t$-student do teste de igualdade entre os coeficientes correspondentes nas duas equações. Valores superiores a dois rejeitam a hipótese nula e indicam que os coeficientes das propostas vencedoras e perdedoras são diferentes. Como não existem lances perdedores quando são realizados apenas 1 lance, não é possível estimar o efeito deste fator no modelo "perdedor" e portanto a linha está omitida. Por limitação da rotina adotada, também estão omitidos as medidas de incerteza dos estimadores dos parâmetros não lineares (rho, sigma).

\footnotetext{
${ }^{8}$ Vale mencionar que foram realizados exercícios com outras variáveis macroeconômicas como taxa de câmbio e aversão ao risco, que não alteraram qualitativamente os resultados obtidos.

${ }^{9}$ Os lances inferiores a R $\$ 48$ Milhões feitos por consórcio de empresas possuem beneficios fiscais. No entanto verificou-se que esta variável indicadora não foi estatisticamente significativa nos modelos e por isto foi excluída da tabela de resultados. De fato, a grande maioria dos lances (72\%) é de valor inferior ao montante de $\mathrm{R} \$ 48$ Milhões, o que talvez explique este resultado.
} 
Tabela 9: Estimações do Modelo

\begin{tabular}{l|c|c|c|c|c|c|c}
\hline & \multicolumn{3}{|c}{ Vencedor } & \multicolumn{2}{c}{ H0 } & \multicolumn{2}{c}{ Perdedor } \\
\cline { 2 - 8 } & $\begin{array}{c}\text { coef1 } \\
\alpha v\end{array}$ & desvpad & $p$-value & coef1 = coef2 & $\begin{array}{c}\text { coef2 } \\
\alpha p\end{array}$ & desvpad & $p$-value \\
\hline Risco Brasil & -0.03 & 0.00 & 0.001 & 3.2 & -0.01 & 0.00 & 0.001 \\
TIR & 0.89 & 0.17 & 0.001 & 2.4 & 0.38 & 0.13 & 0.001 \\
$n=1$ & -0.30 & 0.03 & 0.001 & & & & \\
$n=2$ & -0.19 & 0.03 & 0.001 & 1.6 & -0.13 & 0.03 & 0.001 \\
$n=3$ & -0.13 & 0.03 & 0.001 & 0.5 & -0.11 & 0.02 & 0.001 \\
$n=4$ & -0.10 & 0.03 & 0.010 & 0.3 & -0.11 & 0.02 & 0.001 \\
$n>4$ & 0.02 & 0.04 & 0.640 & 0.2 & 0.01 & 0.02 & 0.660 \\
constante & 0.45 & 0.04 & 0.001 & & 0.19 & 0.02 & 0.001 \\
Inv. Mills & -0.07 & 0.02 & 0.010 & & 0.09 & 0.03 & 0.001 \\
rho & -0.57 & & & & 0.67 & & \\
sigma & 0.11 & & & & 0.14 & & \\
\hline
\end{tabular}

Fonte: Elaboração Própria.

A Tabela 10 apresenta os resultados para a equação (1) que equivale a probit do vencedor, explicada a partir de características intrínsecas do proponente.

Tabela 10: Probit da Condição Vencedor

\begin{tabular}{l|c|c|c}
\hline & coef & desvpad & $p$-value \\
\hline Estatal $^{*}$ & 0.94 & 0.20 & 0.001 \\
Estrangeira* $^{*}$ & -0.14 & 0.20 & 0.490 \\
Nacional $^{*}$ & -0.41 & 0.21 & 0.050 \\
Consórcio & 0.08 & 0.20 & 0.700 \\
Sinergia & 0.27 & 0.15 & 0.080 \\
const & -0.97 & 0.20 & 0.001 \\
\hline Fonte: Elaboração Própria. \\
* indica a participação da empresa estatal, estrangeira \\
ou nacional, de forma isolada ou em consórcio.
\end{tabular}

Os resultados mostram que:

a) A probabilidade de vencer é explicada (significante a 1\%) pela condição de empresa proponente ser ou se associar à empresa estatal e marginalmente devida à existência de sinergias e ganhos de escalas (significante a 8\%), mas não é explicado pela formação de consórcio ou da proponente ser ou associar-se a uma empresa estrangeira. Vale mencionar que o modelo probit relativo à condição do perdedor é, por definição, igual ao resultado apresentado, mas com o sinal trocado;

b) Os coeficientes relativos ao Risco Brasil e à TIR são significativos e apresentam sinal esperado, ou seja, menor Risco Brasil e maior rentabilidade esperada, maiores são os deságios, sendo mais importantes para determinação dos deságios dos lances vencedores que perdedores. Uma explicação razoável é 
de que o proponente vencedor possua um maior e melhor conjunto de atributos e informação em detrimento do proponente perdedor;

c) O número de proponentes é significativo, exceto para maiores que 4, indicando a partir de 4 proponentes o grau de concorrência sobre os deságios não é relevante, e os coeficientes são estatisticamente iguais seja para os lances vencedores quanto perdedores;

d) O grau de concorrência aumenta o deságio de forma não linear, ou seja, lotes com apenas um proponente temos deságios $30 \%$ menores do que os com quatro proponentes ( $10 \%$ menores);

e) O coeficiente da inversa de Mills é significativo nos dois modelos. Isto indica que estudos que ignoram a endogeneidade da clivagem (vencedor/perdedor) ou que focam apenas nos lances vencedores são viezados e podem conduzir a conclusões impróprias.

\section{CONCLUSÕES}

O estudo investigou os determinantes dos altos deságios praticados nos leilões das linhas de transmissão e subestações no setor elétrico brasileiro entre 1999 e 2010, através de um modelo econométrico baseado no modelo de Roy apresentado em Cameron e Trivedi (2005) e no estimador proposto por Heckman (1979). Tal modelo se caracteriza por explicar o deságio de cada grupo vencedor e perdedor - onde a pertinência ao grupo é determinada endogenamente. O modelo analisa os deságios a partir de variáveis observadas e não observadas (fatores latentes) cujo efeito é revelado através da heterogeneidade dos coeficientes entre os grupos vencedor e perdedor. Dessa forma, o modelo parte do conjunto total de lances (vencedores e perdedores) e explicita a heterogeneidade entre o grupo vencedor e perdedor; além de corrigir o viés devido à endogeneidade desta classificação (vencedor/perdedor). $O$ objeto de pesquisa se justifica na medida em que estudos que focam apenas nos lances vencedores ou que ignoram a correção devido à endogeneidade da seleção do grupo vencedor podem levar a conclusões impróprias.

Nesse estudo concluímos que:

i) lances realizados por estatais (isoladas ou em consórcios) tem $50 \%$ de probabilidade de vencer, e segundo este critério ser ou associar-se a estatais em consórcio aumenta a probabilidade de vencer o leilão;

ii) há indicações que as estatais tem participado dos leilões em intensa parceria com o setor privado nacional;

iii) a probabilidade de vencer os leilões também se deve à existência de sinergias e ganhos de escala devido à empresa já possuir investimentos na região do lote a ser leiloado;

iv) os deságios são em parte explicados pelo menor risco Brasil e por uma maior rentabilidade do empreendimento, sendo mais importante para determinação dos deságios dos lances vencedores que perdedores, provavelmente devido a um maior e melhor conjunto de atributos e informação do proponente vencedor;

v) a estatal isolada apresenta o maior deságio médio (29\%);

vi) a média dos deságios dos lances classificados como destoantes (36\%) é praticamente o dobro da média dos demais deságios (23\%); sendo que a estatal líder apresenta o maior número (57\%) de lances classificados como destoantes com deságios médios da ordem de $40 \%$, indicando maior propensão a característica conhecida como "maldição do vencedor"; 
vii) o número de concorrentes é significativo para explicação dos deságios, uma vez que lotes com menos de três proponentes resultaram em pequeno de deságio médio (12\%), e os demais lotes, com maior concorrência, apresentaram deságios médios de $24 \%$;

viii) o grau de concorrência influencia o deságio de forma não linear, e a partir de quatro proponentes o grau de concorrência não é mais relevante para os deságios;

ix) o efeito das variáveis não observadas, representada pela condição de vencedor no leilão, é estatisticamente significativo, indicando que estudos que focam apenas nos lances vencedores ou que ignoram a correção devido à endogeneidade da seleção do grupo vencedor podem conduzir a conclusões impróprias.

As informações disponíveis sobre os grupos participantes do leilão, identificação das sinergias, interdependência e ganhos de escala potencial são muito limitadas e sua sofisticação depende do grau de informação disponível. Propomos essa questão como objeto de futuras extensões a esse trabalho. Outra extensão possível refere-se à análise da dinâmica do leilão através de informações específicas das propostas na primeira fase (envelope selado) e segunda fase (concorrência viva-voz), além de ampliar o período de estudo para os leilões realizados a partir de 2011.

\section{BIBLIOGRAFIA}

Cameron, A. C. \& Trivedi, P. K. (2005). Microeconometrics: Methods and Applications. Cambridge University Press, New York.

Capen, E., Clapp, V., \& Campbell, W. (1971). Competitive bidding in high-risk situations. Journal of Petroleum Technology, 23:641-653.

Carlos, A. \& Saraiva, J. (2010). Strategic behaviour of winning bids in the Brazilian transmission auctions. Technical report, Graduate School of Economics, EPGE/FGV.

Castro, N. \& Brandão, R. (2007a). Competitividade nos leilões de linhas de transmissão. Working paper, GESEL - UFRJ.

Castro, N. \& Brandão, R. (2007b). Os leilões de linhas de transmissão e o Risco Brasil. Revista GDT, 3:58-59.

CC-MED (2002). Review of asset valuation methodologies: Electricity lines businesses' system fixed assets. Commerce Comission. Ministry of Economic Development, New Zealand. Disponível em: http://www . comcom.govt.nz/valuation-of-the-regulatory-asset-base/.

Dutra, J. \& Menezes, F. (2002). Hybrid auctions. Economic Letters, 77:301-307.

Gandal, N. (1997). Sequential auctions of interdependent objects: Israeli cable television licenses. The Journal of Industrial, XLV:227-244. Oxford, England.

Heckman, J. (1979). Sample selection bias as a specification error. Econometrica, 47:153-161.

Hirota, H. (2006). O mercado de concessão de transmissão de energia elétrica no Brasil. Dissertação de mestrado, Faculdade de Economia, Administração e Contabilidade de Ribeirão Preto, Universidade de São Paulo, Ribeirão Preto.

Klemperer, P. (2002). What really matters in auction design. Journal of Economic Perspectives, 16:169-189. American Economic Association . 
Motta, L. \& Ramos, F. (2011). Efeito Estratégico sobre os Leilões de Linhas de Transmissão Brasileiros: O Caso da Interdependência. In XLIII Simpósio Brasileiro de Pesquisa Operacional, São Paulo.

Thaler, R. (1988). Anomalies: The winner's curse. Journal of Economic Perspectives, 2:191-202.

Tukey, J. W. (1977). Exploratory Data Analysis. Addison-Wesley. 